\title{
Peculiarities in the demand forecast for an HSRL connecting two countries. Case of Kuala Lumpur - Singapore HSRL
}

\author{
Aldara Tadeo \\ Transport consultant, Ineco, Spain \\ Patricia Rey \\ Technical manager, Ineco, Spain
}

\begin{abstract}
The High Speed Rail Line (HSRL) between Kuala Lumpur (KL) and Singapore (SP) is aimed at reducing to 90 minutes the travel time between two of Southeast Asia's most vibrant and fast-growing economic engines.
\end{abstract}

Ineco was hired by the Government of Malaysia to forecast the demand for the future HSRL. The Government of Malaysia played a key role when firstly defining the current situation on the corridor and the features of the HSRL, and then providing Ineco with the studies previously developed by them.

Besides the obvious interest in connecting both capital cities, Malaysia wishes to promote the economic development of intermediate cities, whereas Singapore, a 718 squarekilometer city-state and island, is interested in improving its connection with Nusajaya - a Malaysian city that is being developed just across the border and regarded as land reserves.

Two kinds of services will be provided on the new rail infrastructure: non-stop services between KL and SP, and services with 6 intermediate stops on the Malaysian side.

The aim of this paper is to describe the process to forecast the demand for the HSRL Kuala Lumpur - Singapore by focusing on the peculiarities of an international HSRL. Identifying these aspects at an early stage is vital to get a better demand estimate and to reconsider the HSRL characteristics if necessary.

The demand for the new line was calculated by applying a three-step model: generation model, distribution model and modal split model.

In 2030, 10 years after the opening year, the HSRL is expected to move $23-26$ million passengers - baseline and optimistic scenarios, respectively -, which represents an $18.5 \%$ share of the total demand on the corridor. The demand for the KL-SP pair will account for $30 \%$ the demand for the future HSRL. 


\section{HSRL CONTEXT}

Ineco was hired by the Government of Malaysia to forecast the demand for the future HSRL. Although Ineco's study was developed at a preliminary stage - Malaysia and Singapore keep discussing about the characteristics of the future HSRL - , it does not start from scratch, as both Malaysia and Singapore had previously carried out feasibility studies.

The peculiarities of the future HSRL Kuala Lumpur (KL) - Singapore (SP) are mostly the result of the connection of two countries with different living conditions. Whereas both countries have a GDP around 300,000 million US \$ (World Bank, 2013), Malaysia's population is more than five times Singapore's population (International Monetary Fund, 2013), which means that the GDP per capita in Singapore is five times the GDP per capita in Malaysia.

Therefore, besides the obvious interest in connecting both capital cities, Malaysia wishes to promote the economic development of intermediate cities. On the other hand, Singapore, a 718 square-kilometer city-state and island, is interested in improving its connection with Nusajaya - a Malaysian city that is being developed just across the border and regarded as land reserves.

The future HSRL will connect eight cities along a coastal route. Two kinds of services will be provided on the new rail infrastructure: non-stop services between KL and SP, and services with 6 intermediate stops on the Malaysian side - Putrajaya, Seremban, Melaka, Muar, Batu Pahat and Nusajaya. The bottom left image shows the location of Peninsular Malaysia and Singapore. The bottom right image depicts the stops of the future HSRL.

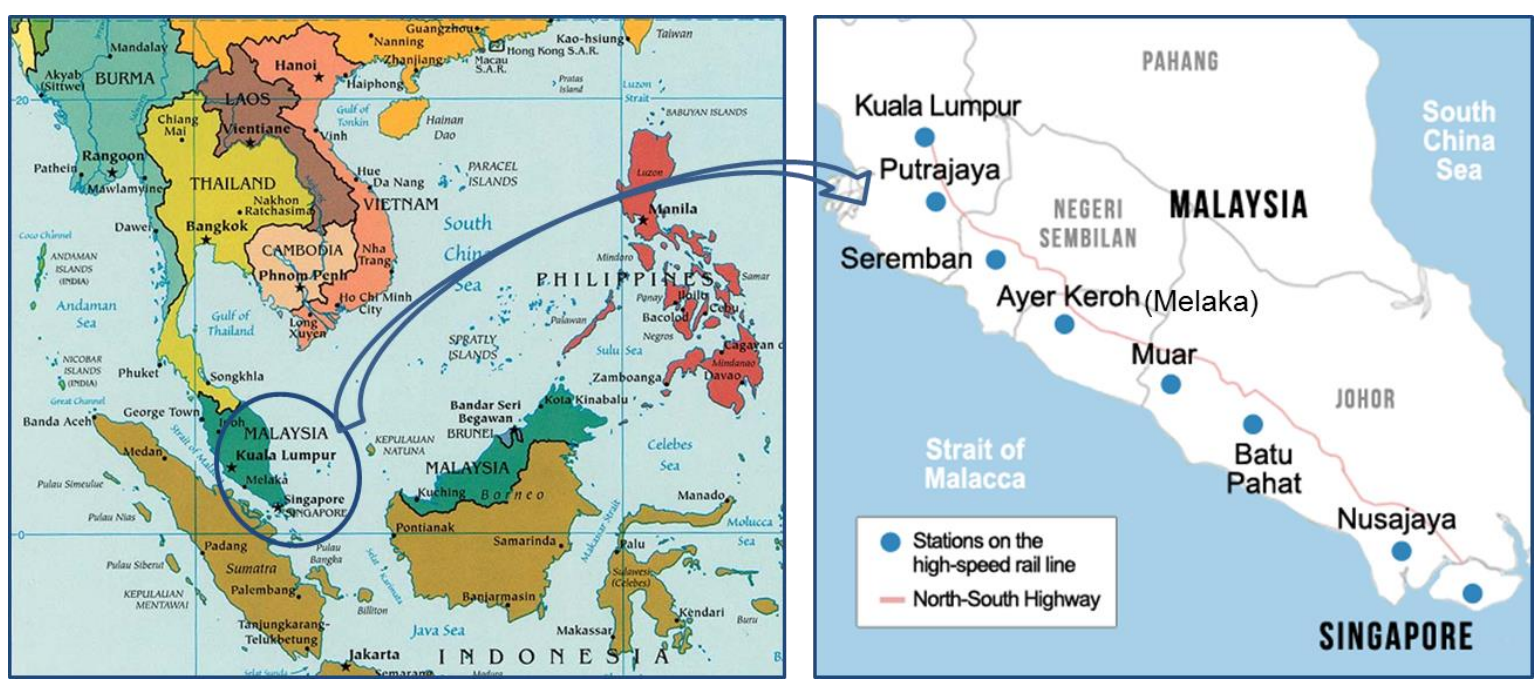

Fig. 1 - Location of Peninsular Malaysia and Singapore (left). Stations on the future HSRL (right)

The corridor area defined by the new HSRL - estimated by considering a circumference 
with a thirty-kilometre radius - comprises 16,287,718 inhabitants and 8,413,691 people employed, which means $46.6 \%$ of the population in Malaysia and Singapore and $50.4 \%$ of the people employed in both countries.

\section{CURRENT SITUATION ON THE KUALA LUMPUR - SINGAPORE CORRIDOR}

The Kuala Lumpur - Singapore route is serviced by 3 main modes of transport: air, road and an existing intercity rail network.

The main road connecting Kuala Lumpur with Johor Bahru is a toll dual carriageway. All the cities along the corridor are connected by bus services, which are provided by several companies on each route.

Two bridges link Singapore Island to Peninsular Malaysia. The functionality of these bridges - Second Link and Causeway Link - is described in the figure below.

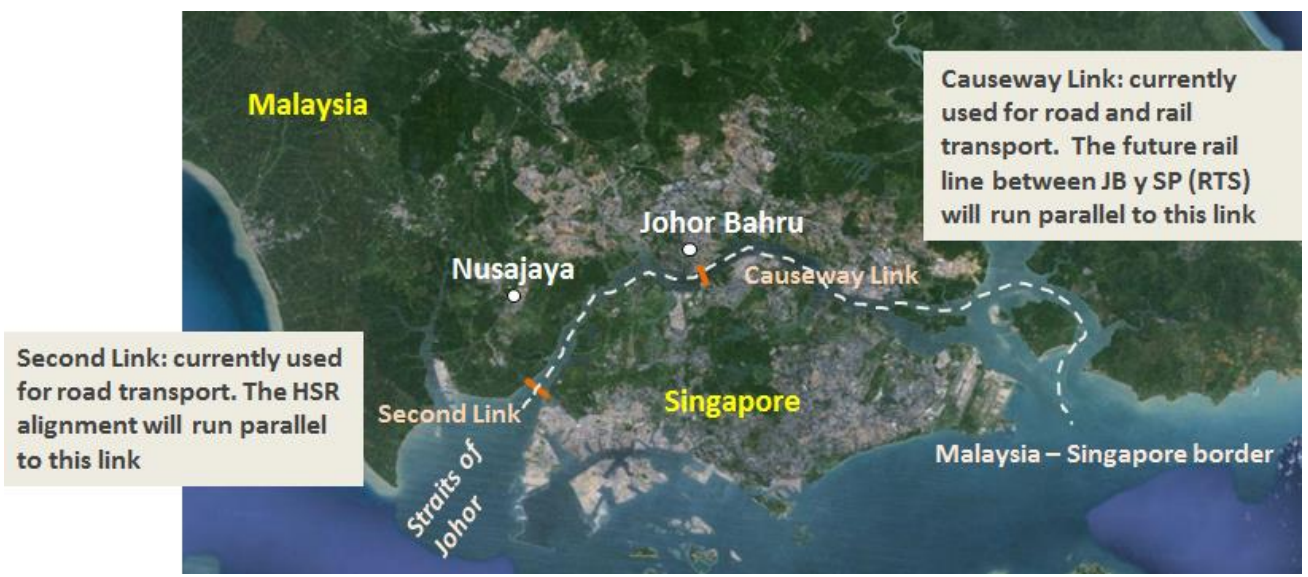

Fig. 2 - Land connection between Peninsular Malaysia and Singapore

The crossing of the border by land, especially by road, takes long. Cross-border passengers travelling by bus are required to disembark twice (once in Malaysia and once in Singapore) to obtain customs and immigration clearance before proceeding to their final destination.

Crossing the Straits of Johor by road implies to pay a charge, which is not symmetrical, i.e., the charge depends on the trip direction. Additionally, Singapore Land Transport Authority requires foreign-registered cars to pay daily Vehicle entry permit (VEP) fees for each day the vehicles are kept or used in Singapore.

As for the intercity rail, another drawback is the Singapore station location (Woodlands). This station is near the border with Malaysia so it is not integrated with the city.

In addition to the rail services connecting Kuala Lumpur with Singapore (intercity rail), the 
future HSRL will have to compete with the following rail services in part of the corridor:

- KTM Komuter: the commuter train of the Greater Kuala Lumpur connects Kuala Lumpur with Seremban, two of the stops of the future HSRL.

- Express Rail Link (ERL): the line connecting Kuala Lumpur and the Kuala Lumpur International Airport (KLIA) has one stop at Putrajaya.

- Rapid Transit System (RTS): rail line planned to strengthen the connectivity between Johor Bahru and Singapore. Figure 2 shows the alignment of this system.

There are five airports located along the HSRL corridor. However, only two relations will have to compete with the new rail services: Kuala Lumpur - Singapore (KL-SP) and Kuala Lumpur - Johor Bahru (KL-JB).

The next figure shows current transport infrastructure on the corridor and the future HSRL.

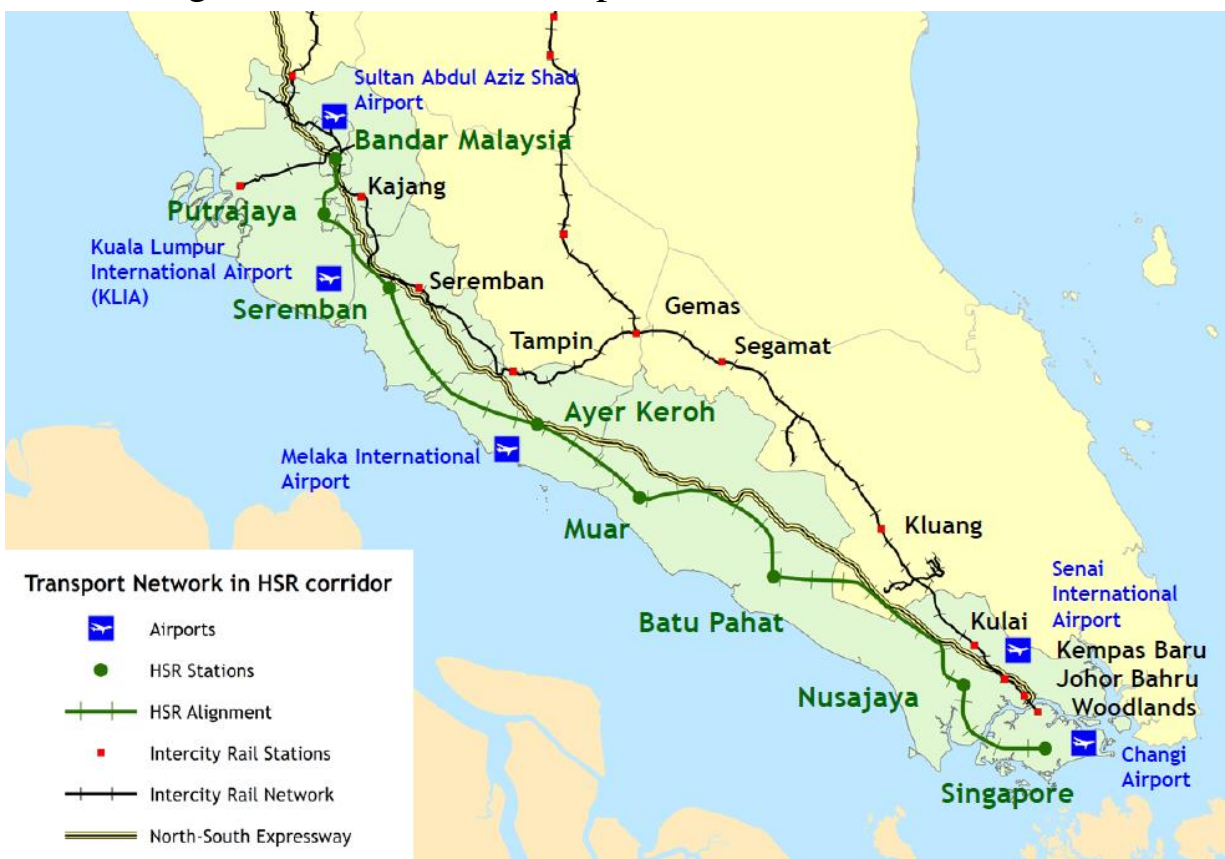

Fig. 3 - Transport infrastructures on the corridor, including future HSRL

The demand for transport between pairs along the corridor in the base year - 2013 - was estimated from the previous study developed by McKinsey (2013), whose most recent data dates back to 2011. Therefore, data from incumbent operators were analysed in order to update the figures included in the afore-mentioned study.

Moreover, a fieldwork campaign was conducted in Putrajaya, Nusajaya and KLIA in order to complete the existing information.

The collaboration of transport operators and managers is vital to accurately determine current transport supply and demand as this information is not always available to the public. In this case, current figures of rail demand were not provided to Ineco, so some hypotheses had to be made to update the figures in the previous study. 
The next figure depicts the modal split on the corridor in 2013.

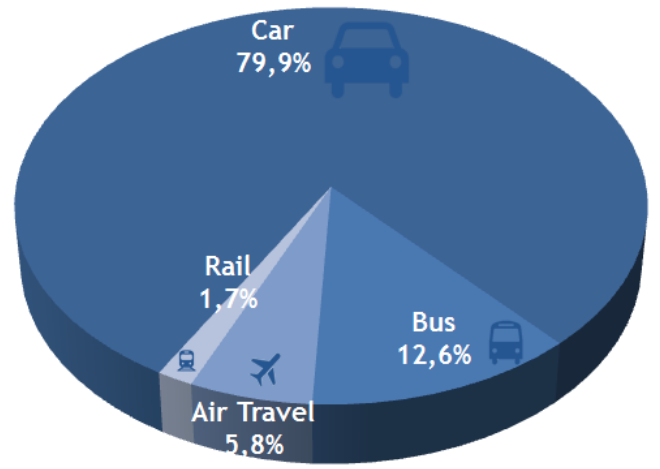

Fig. 4 - Modal split on the corridor in the base year

\section{METHODOLOGY TO ESTIMATE THE DEMAND FOR THE HSRL}

The demand for the new line was calculated by applying a three-step model: generation model, distribution model and modal split model.

The socioeconomic variables that fit best to actual mobility were Population and GDP. Population forecasts developed by the United Nations (2014) and GDP forecasts by the Asian Development Bank (2011) were used to build two growth scenarios - baseline and optimistic scenarios. The forecasts for population and GDP were then entered into the regression that explains actual mobility.

The demand diverted by the new HSRL was estimated by applying a modal split model. This model was adjusted by using the Stated Preference Surveys conducted previously. In these surveys, passengers were required to state their preferred means of transport (between the new HSRL and their current mode), according to different levels of price and travel time of HSR service that were shown to them.

In order to take into account the different criteria that can be followed during the modal choice process, the obtained sample was split by type of current mode and the origin/destination pair (O/D pair) of the journey (e.g. Malaysian internal journeys and Malaysia-Singapore journeys).

The results of the modal split model are shown in the next point. Despite being planned to start operation in 2020, it was considered that the demand is not captured immediately, but gradually in a six-year period (commonly known as ramp-up period).

The demand induced by the HSRL is regarded as $18 \%$ of the demand captured from the existing modes, value aligned with the results of the fieldwork campaign and a 
international benchmark. Induced demand is expected to take 10 years before achieving its steady state.

Besides the HSRL demand estimates, two additional analyses were carried out.

Firstly, a sensitivity analysis to the location of Singapore station. The figure below shows the three locations analysed. The analysis was carried out by modifying HSRL travel times and fares, as the transport model developed was macroscopic. The stop at Marina (most likely location) would imply a higher fare and lower travel time than the stop at Tuas, as the travel distance to the former is higher and the travel time to the main points of interest in Singapore is lower.

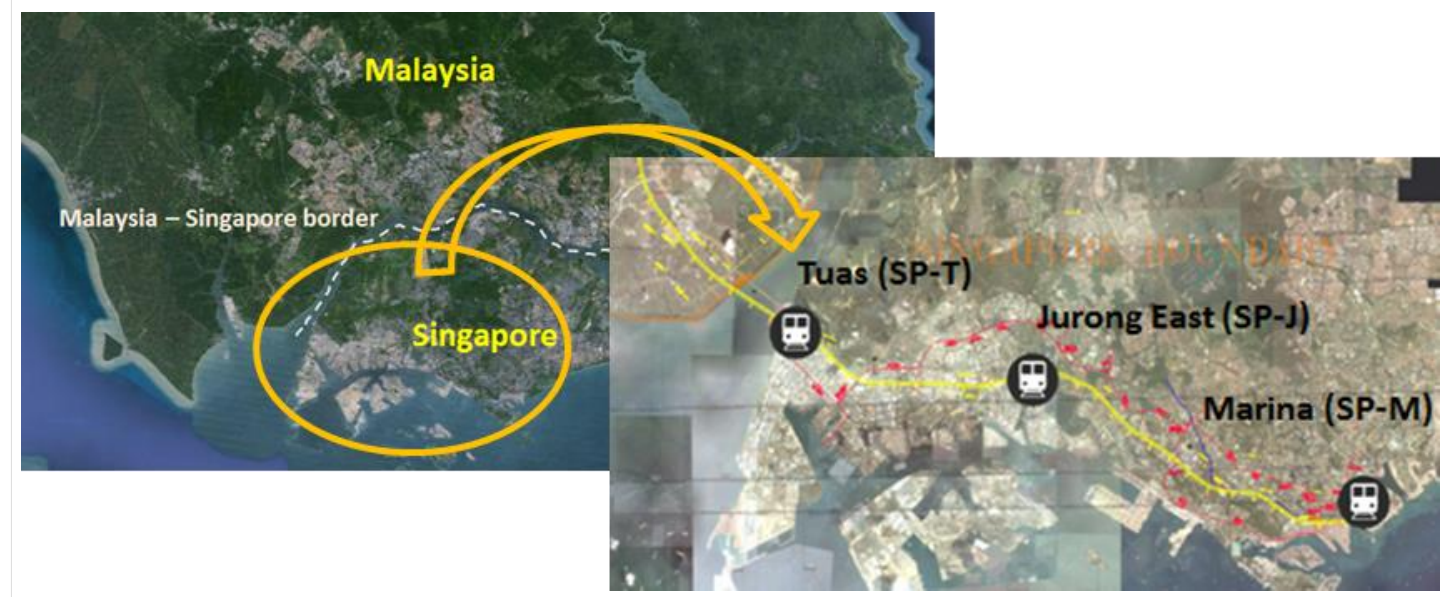

Fig. 5 - Alternatives for Singapore station

Secondly, analysis of revenue maximisation - HSRL fares that would maximise HSRL revenue. A demand sensitivity analysis to fare variations was done for every mode and travel segment within every O/D pair. This allows knowing how much the HSRL demand changes for a given variation in HSRL fare. After that, a regression analysis was developed to determine mathematically which increment in fare maximises the increment in revenue for all the O/D pairs as a whole.

\section{RESULTS}

Modal share of the HSRL is expected to be around 10\%-25\% in the different O/D pairs. Nevertheless, routes where air connections are available have higher shares of HSRL - KLSG (45.2\%) and KL-JB (28.5\%).

The following figure shows how HSRL demand is distributed among the existing transport modes on the corridor and on the KL - SP pair. It can be observed that HSRL demand mainly comes from the car (57.3\%) except for O/D pairs connected by air. 
HSRL demand on the corridor comes from:

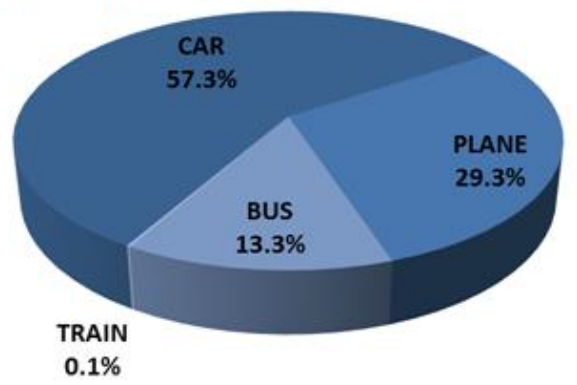

HSRL demand on Kuala Lumpur-Singapore pair comes from:

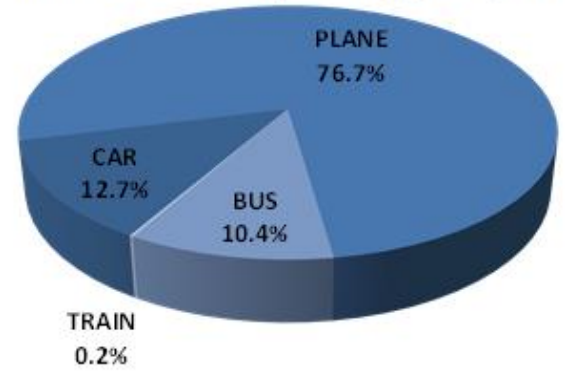

Fig. 6 - Origin of HSRL demand

In 2030, 10 years after the opening year, the HSRL is expected to move $23-26$ million passengers - baseline and optimistic scenarios, respectively -, which represents an $18.5 \%$ share of the total demand on the corridor. The demand for the KL-SP pair will account for about $30 \%$ the demand for the future HSRL.

The next figure depicts the modal split on the corridor once the HSRL reaches its total demand (from 2030 onwards).

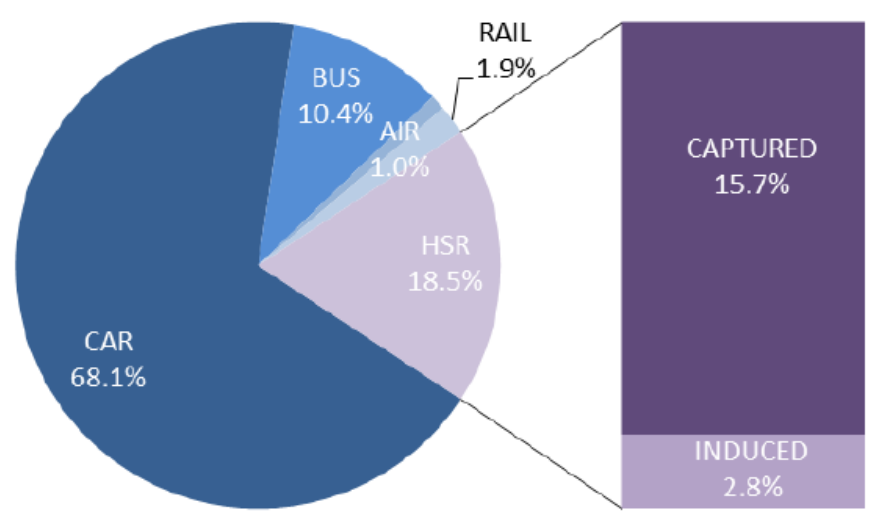

Fig. 7 - Final modal split

The results shown above correspond to Singapore station at Marina. Locating Singapore station at Jurong would imply a HSRL demand 3\% lower than at Marina whatever the scenario considered. If Singapore station were located at Tuas, HSRL demand would be 7\% lower than at Marina. Marina implies lower travel time but a higher cost than Jurong or Tuas, so when considering all the alternative modes, savings in time are more important to passengers than savings in money.

The revenue maximisation analysis shows that the HSRL fares taken as a reference (base situation) would have to increase between 30 and $40 \%$ to maximise HSRL revenues. Adopting these fares would imply an increase in HSRL income of $4-5 \%$ but also a decrease in HSRL demand of $20-25 \%$.

\section{CONCLUSIONS}


This study provided the Malaysian Government with an estimate of the future use of the HSRL and its impact on the transport demand on the corridor Kuala Lumpur - Singapore.

Nevertheless, a common approach to the new HSRL is still lacking, so the information taken as a reference came exclusively from the Malaysian side.

Some peculiarities identified were not considered in this study due to the lack of detailed information. It is the case of the asymmetry in the charge to cross the Straits of Johor, which was not considered since the information available was not detailed enough to assume demand was not symmetrical. Another example is the fact that the fare of the bus between KL and SP is not the same in both countries.

The fact that HSR services with intermediate stops will have to stop at the border to comply with customs duties is another pending issue. This situation does not seem appropriate for a HSR service and could be avoided by implementing customs services in intermediate stations too.

Once the afore-mentioned peculiarities are solved, a further step would be to incorporate different fares per O/D pair by taking into account the travel class, type of user, period of the day, type of ticket, advance in the reservation, etc. This will provide a better approach to HSRL demand and revenues.

\section{REFERENCES}

Asian Development Bank. (2011). Asia 2050, Realizing the Asian Century. Retrieved from http://www.unido.org/fileadmin/user_media/UNIDO_Worldwide/Asia_and_Pacific_Progr amme/Documents/AsianDevelopmentBankreport_asia-2050.pdf

International Monetary Fund. (2013). Population 2013. Retrieved from http://www.imf.org/external/data.htm

McKinsey. (2013). High Speed Rail Feasibility Study - Phase 1B Project - Demand and Revenue. 2013.

United Nations. (2014). World Population Prospects. Retrieved from http://esa.un.org/unpd/wpp/Download/Standard/Population/

World Bank. (2013). Gross Domestic Product 2013. Retrieved from http://data.worldbank.org/indicator/NY.GDP.PCAP.CD 